\title{
Endurance Training on Low-Carbohydrate and Grain-Based Diets: A Case Study
}

\author{
Richard R. Rosenkranz, Chad M. Cook, and Mark D. Haub
}

\begin{abstract}
Purpose: To illustrate the effects of low-carbohydrate (LC) and grain-based (GB) diets on body composition, biomarkers, athletic training, and performance in an elite triathlete. Methods: The athlete followed 2 dietary interventions for $14 \mathrm{~d}$ while maintaining a prescheduled training program. Pre- and postintervention measurements for each diet included plasma and serum samples, resting energy expenditure, body composition, and a performance bike ride. Results: Compared with the GB diet, the LC diet elicited more disruptions to training and unfavorable subjective experiences. Total cholesterol, HDL cholesterol, LDL cholesterol, ratings of perceived exertion, and heart rate were elevated in the LC diet. Blood insulin, resting lactate, postexercise lactate, and C-reactive protein were lowest in the LC diet. Conclusion: The LC diet resulted in both favorable and unfavorable outcomes. The primary observation was a disruption to scheduled training on the LC diet. Researchers should consider how the potential mediating effect of disruptions to training could influence pretest-posttest designs.
\end{abstract}

Key Words: high-fat, exercise, performance, triathlon, triathlete

Interest in macronutrient intake and exercise performance has increased with the current obesity epidemic (29). Several investigations have tested the effects of differing amounts of carbohydrate and fat intake on human-performance outcomes $(3,13,18,20,21,25,26,31)$. It is also evident that low-carbohydrate (LC) diets are capable of decreasing body weight and increasing insulin sensitivity $(30,32)$; however, the effects of lower carbohydrate intake (commensurate with higher intakes of fat and protein) on exercise performance are equivocal (9). Furthermore, there is a paucity of research examining the effects of these LC diets on daily exercise regimens and training for athletic competition. There are limited data to indicate whether the performance differences observed in studies from before and after dietary interventions are a result of the actual dietary intervention alone or of perturbations in exercise regimens (volume, frequency, intensity, and combinations thereof).

Endurance athletes have explored various avenues to improve sustained performance both by reducing body weight (6) and by increasing the contribution of fatty

Rosenkranz is with the Community Health Institute, and Cook and Haub, the Human Nutrition Dept, Kansas State University, Manhattan, KA 66502. 
acids as a fuel source, and LC diets seem to facilitate both processes. Preferentially tapping into an athlete's relatively ample fat stores might prolong the capacity to utilize the more limited glycogen stores when increased power output is desired. For example, acute elevations in serum free fatty acids, via a heparin injection, elicit a marked increase in free-fatty-acid oxidation and a concomitant sparing of muscle glycogen (22), thus potentially allowing for prolonged endurance capacity. Likewise, chronic intake of a high-fat, LC diet might attenuate the adaptations that favor carbohydrate oxidation and ultimately enhance the capacity to oxidize more fat during exercise (20). Moderately LC diets such as the 40/30/30, or "Zone," diet are also purported to benefit elite endurance athletes (7). More recent research has characterized adaptations from high-fat, LC diets in terms of "glycogen impairment" rather than glycogen sparing $(7,11)$ because of observations of the down-regulation of carbohydrate metabolism coupled with compromised ability to perform high-intensity exercise.

A presumed deleterious consequence of an LC diet is decreased preexercise muscle-glycogen content $(20,24)$. A few studies, however, have shown significant improvements in exercise performance with higher fat diets $(13,20,21,26)$. This increased ability to utilize more fatty acids for fuel has been attributed to increased oxidative enzymes (16), increased mitochondrial density (16), greater storage and utilization of intramuscular triglyceride (28), and enhanced muscle uptake of plasma free fatty acids (12).

Although evidence (27) indicates that dietary intake has effects on exercise performance (positively or negatively), one critical aspect that has been neglected in most, if not all, studies is a report of the effects on daily training. That is, pre-post performance testing is a typical outcome measure, and it is not evident whether the dietary intervention only affected the assessed athletic performance or also affected daily exercise regimen in the process. Furthermore, with longer interventions, the exercise regimen itself might have a strong influence on the performance outcome. Thus, the observed changes from pretest to posttest could be confounded by dietary effects on the continuing exercise regimen itself. With these factors in mind, the purpose of this case study was to illustrate the daily exercise regimen and performance tests, along with biomarkers of health, for 2 dietary interventions, an LC diet and a grain-based (GB) diet, in an elite triathlete.

\section{Method}

The subject of this project was a 34-year-old man who had been consistently involved in endurance-based athletic training and competition since age 15. After an intercollegiate career of middle-distance and distance running, he took up the sport of triathlon and became a national-class elite competitor in swim-bike-run events. The athlete was self-coached during the preceding $2 \mathrm{y}$ and reported generally good adherence to a preplanned training program designed for short-course triathlons. Short-course triathlons are competitions having a range of distances that take top competitors between $50 \mathrm{~min}$ and $2 \mathrm{~h}$ to complete. These include the "sprint" distance of a 750-m swim, $20 \mathrm{~K}$ bike ride, and $5 \mathrm{~K}$ run; "international" distance of $1.5 \mathrm{~K}$ swim, $40 \mathrm{~K}$ bike ride, and $10 \mathrm{~K}$ run; and various other distances tailored to individual race venues. The athlete employed periodized training methods in an 
annual training plan, and this was evident in his training logs. His typical combined training volumes for swimming, biking, running, and resistance training totaled $10-16 \mathrm{~h} / \mathrm{wk}$ over the past few years.

\section{Daily Training Logs}

Before enrollment in this study, the athlete outlined a specific training plan of his intended workouts, without regard to dietary alteration. During the study, he maintained a detailed exercise log. All workouts were recorded daily, including interval splits, perceived exertion, and other subjective reactions to the training. These data were handwritten by the athlete in a training log. The athlete provided informed consent as part of a larger dietary-intervention study approved by the institutional review board at Kansas State University. This case study was conceived after the athlete had completed the trials in the dietary-intervention study, making post hoc interpretation a necessity but also tempering potential bias in subjective report of daily training.

\section{Exercise Testing}

Before any dietary intervention, the subject performed an initial fitness test $\left(\mathrm{VO}_{2 \max }\right)$, which was used to establish the exercise intensity of his subsequent trials. All exercise testing was performed on an electronically braked cycle ergometer that was individually adjusted for the subject (Cardgirus Medical, v 1.2, Guipúzcoa, Spain). A 1-way mouthpiece was used to direct expired gases to a pneumotachometer and the oxygen and carbon-dioxide analyzers (TrueOne, ParvoMedics, Provo, UT). After at least $30 \mathrm{~min}$, the gas analyzers and flowmeter were calibrated immediately before testing using gases of known concentration $\left(16 \% \mathrm{O}_{2}\right.$ and $\left.4 \% \mathrm{CO}_{2}\right)$ and a 3-L syringe, respectively. A ramp protocol was used, in which the initial work rate was $100 \mathrm{~W}$ and the work rate increased $1 \mathrm{~W}$ every $2 \mathrm{~s}(30 \mathrm{~W} / \mathrm{min})$ thereafter until the subject could not maintain a minimal cadence of 60 revolutions $/ \mathrm{min}$. The final work rate was used to calculate the work rate for the subsequent exercise-performance efforts $\left(75 \%\right.$ of $\left.\mathrm{W}_{\max }\right)$.

\section{Dietary Interventions}

After the $\mathrm{VO}_{2 \max }$ test, the athlete was randomly assigned to start the study with the LC diet. For both LC and GB diets, the athlete was provided the portions of the food he was to consume for the diet that he was assigned to follow. For the LC diet, he was provided $0.8 \mathrm{~g}$ of protein $/ \mathrm{kg}$ body weight per day. The following food items were provided using a 5-d rotating menu: eggs, peanuts, beef jerky, cheddar-cheese cubes, mozzarella string cheese, canned tuna, and canned ham. For the remainder of the LC diet the athlete was provided a list of acceptable food items (including nonstarchy vegetables, meat, fish, poultry, eggs, nuts, and any Atkins-approved product) and unacceptable food items (including fruit, bread, pasta, rice, potatoes, or other potent sources of carbohydrate). The LC diet was based on the 2-wk induction phase of the Atkins diet. The athlete kept a food record of everything he ingested during the last $7 \mathrm{~d}$ of each dietary intervention, as well as $3 \mathrm{~d}$ during the ad libitum period between interventions. 
For the GB diet, the athlete was provided GB food products equivalent in calories to the foods provided in the LC diet. The foods provided for the GB diet included whole-wheat tortillas, whole-wheat bread, cheese pizza, long-grain-rice soup, canned beef ravioli, whole-grain waffles, oatmeal, and whole-grain breakfast bars. The GB diet was based on the U.S. Department of Agriculture food-guide pyramid, with the primary exception of restricting refined-flour pastries (doughnuts, cakes, cookies, etc.), oil-fried foods (such as fried chicken, French-fried potatoes, potato and corn chips, etc.), and hard and soft candies.

For both of the 14-d dietary conditions, the athlete visited the laboratory Monday through Friday to receive his food and have his body weight measured. He received food for the weekend on each Friday. Between the 2 controlled diets, the athlete consumed his normal diet, free of any imposed restrictions. This ad libitum period lasted approximately $5 \mathrm{wk}$.

\section{Blood and Urine Analysis}

After each dietary condition, the subject's urine was collected for a ketosis test using standard keto strips. Before and after each 14-d dietary condition, the athlete visited the laboratory after an overnight fast. First, he rested supine in bed for 40 min to measure his resting metabolic rate, heart rate, and respiratory-exchange ratio via indirect calorimetry (TrueOne, ParvoMedics, Provo, UT). After the metabolism test, body composition was assessed via dual-energy X-ray absorptiometry (GE-Lunar Prodigy v 5.6, General Electric, Milwaukee, WI). A fasting blood sample was then collected for the assessment of glucose (YSI 2300, Yellow Springs, OH), insulin (Alpco Diagnostics, Salem, NH), total cholesterol (Wako Chemicals, Richmond, VA), high-density lipoprotein cholesterol (HDL-C; Wako Chemicals, Richmond, VA), triglyceride (Wako Chemicals), and C-reactive protein (R\&D Systems, Minneapolis, MN). Low-density lipoprotein cholesterol was calculated from the totalcholesterol, HDL-C, and triglyceride levels (10).

\section{Exercise Performance}

The subject warmed up on the cycle ergometer to prepare for the 5-km effort. The intensity of the exercise was set at $75 \%$ of $\mathrm{W}_{\max }$. During the ride, the following parameters were measured: rating of perceived exertion (RPE) (4), power output, heart rate $(\mathrm{HR})$ via radiotelemetry, and oxygen uptake $\left(\mathrm{VO}_{2}\right)$. After the exercise, another blood sample was collected to measure postexercise plasma glucose and blood lactate levels.

\section{Observations}

\section{Dietary}

The relative contributions of fat, carbohydrate, and protein in each diet are displayed in Figure 1 and Table 1. Carbohydrates composed $21.5 \%$, fat $54.7 \%$, and protein $23.5 \%$ of the average $3736 \mathrm{kcal}$ consumed during the final $7 \mathrm{~d}$ of the LC diet. The GB diet contained the following macronutrient composition: $58.7 \%$ carbohydrates, $28.3 \%$ fat, and $12.1 \%$ protein. Compared with the LC diet, the macronutrient intake 
during the GB diet was more representative of the athlete's self-selected diet, which consisted of $68.9 \%$ carbohydrate calories, $19.1 \%$ fat calories, and $12 \%$ protein calories. The average energy intake during the GB diet (3949 kcal/d; Table 1) was higher than during the LC diet ( $3736 \mathrm{kcal} / \mathrm{d})$. Both LC and GB energy intakes were lower than the unrestricted ad libitum energy intake $(4659 \mathrm{kcal} / \mathrm{d})$. Based on his food logs, the athlete reported excellent adherence during each dietary intervention.

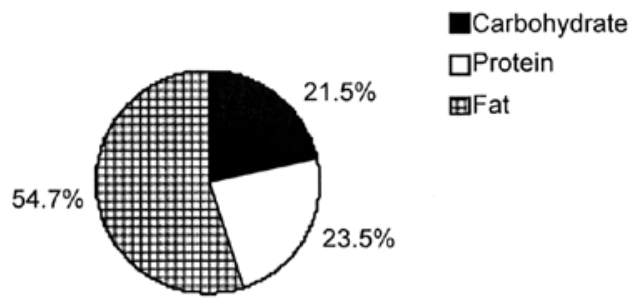

Relative contribution of macronutrients in lowcarbohydrate diet

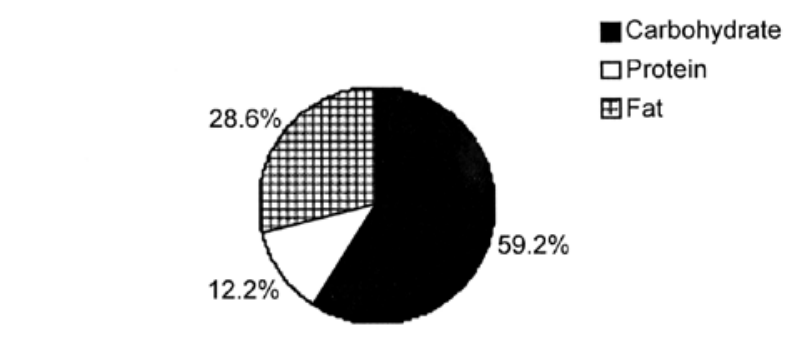

Relative contribution of macronutrients in grainbased diet

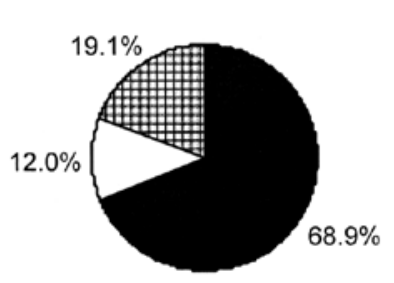

Carbohydrate

口Protein

⿴囗十Fat

Relative contribution of macronutrients in ad libitum diet

Figure 1 - A comparison of fat, carbohydrate, and protein in the 3 dietary conditions. 
Table 1 Summary of Relative Contribution of Macronutrients in 3 Dietary Conditions

\begin{tabular}{lccc}
\hline & \multicolumn{3}{c}{ Diet } \\
\cline { 2 - 4 } & Low carbohydrate & Grain based & Ad libitum \\
\hline Percentage carbohydrate & 21.5 & 58.7 & 68.9 \\
Carbohydrates $(\mathrm{g} / \mathrm{d})$ & 208 & 603 & 822 \\
Percentage fat & 54.7 & 28.3 & 19.1 \\
Fat $(\mathrm{g} / \mathrm{d})$ & 235 & 129 & 102 \\
Percentage protein & 23.5 & 12.1 & 12.0 \\
Protein $(\mathrm{g} / \mathrm{d})$ & 227 & 125 & 143 \\
Total energy $(\mathrm{kcal} / \mathrm{d})$ & 3736 & 3949 & 4659 \\
\hline
\end{tabular}

\section{Anthropometric Measures}

The athlete lost weight on the LC diet (pre $=78.8 \mathrm{~kg}$, post $=75.6 \mathrm{~kg}$; Table 2). Similarly, his body-fat percentage, fat mass, and fat-free mass all decreased on the LC diet. All these variables were lower at posttest on the LC diet than at pretest or at either testing time for the GB diet.

\section{Metabolic Measures}

Table 2 summarizes the metabolic data for each diet. Resting energy expenditure increased from about $1515 \mathrm{kcal} / \mathrm{d}$ at pretest to about $1,585 \mathrm{kcal} / \mathrm{d}$ at posttest during the LC diet, while resting HR remained relatively stable. The athlete's resting energy expenditure increased to a lesser extent during the GB diet, from $1510 \mathrm{kcal} / \mathrm{d}$ at pretest to about $1552 \mathrm{kcal} / \mathrm{d}$ at posttest. Resting HR was slightly lower at pretest before the GB diet. Overall, resting energy expenditure and HR were highest at the end of the LC diet and lowest at the end of the ad libitum condition (GB pretest).

\section{Performance Measures}

Table 3 summarizes the performance data for the end of each dietary condition. With $\mathrm{VO}_{2}$ and power output relatively constant throughout tests, the exercise HR and RPE scores were higher during the posttest after the LC diet.

\section{Biomarkers}

Tables 2 and 3 display the blood values before and after each diet. The subject's total cholesterol, HDL-C, and LDL-C increased from pretest to posttest in the LC condition, and these values were higher than either pretest or posttest for the GB diet condition. Triglycerides, resting glucose, postexercise lactate, and insulin decreased from pretest to posttest in the LC condition, and these values were lower than at either pretest (ad libitum posttest) or posttest for the GB condition. C-reactive-protein values before and after the GB diet were higher than before and after the LC diet. Based on testing of the urine samples, the LC diet induced mild ketosis and the GB diet did not. 
Table 2 Summary of Pretest-to-Posttest Anthropometric, Metabolic, and Biomarker Data for the Low-Carbohydrate (LC) and Grain-Based (GB) Conditions

\begin{tabular}{lcccc}
\hline Variable & LC pretest & LC posttest & GB pretest & $\begin{array}{c}\text { GB } \\
\text { posttest }\end{array}$ \\
\hline Anthropometric measures & & & & \\
weight (kg) & 78.8 & 75.6 & 77.1 & 77.7 \\
\% body fat & 8.0 & 6.4 & 7.6 & 7.5 \\
fat mass (kg) & 6.0 & 4.7 & 5.7 & 5.6 \\
fat-free mass (kg) & 68.9 & 67.9 & 69.5 & 69.7 \\
Metabolic measures & & & & \\
HR Rest $($ beats/min) & 47.3 & 47.8 & 45.6 & 47.0 \\
resting energy & & & & \\
expenditure (kcal/d) & 1514.8 & 1584.8 & 1510.0 & 1551.8 \\
Biomarkers & & & & \\
total cholesterol & 152 & 178 & 163 & 160 \\
HDL & 43 & 60 & 53 & 53 \\
LDL & 84 & 98 & 89 & 83 \\
triglycerides & 126 & 96 & 104 & 118 \\
\hline
\end{tabular}

${ }^{\mathrm{a} A l s o}$ ad libitum posttest.

Table 3 Summary of Performance-Ride Data for Each Dietary Condition

\begin{tabular}{lccc}
\hline & \multicolumn{3}{c}{ Diet } \\
\cline { 2 - 4 } Variable & Low carbohydrate & Ad libitum $^{\text {a }}$ & Grain based \\
\hline $\mathrm{HR}($ beats $/ \mathrm{min})$ & 185 & 178 & 180 \\
$\mathrm{VO}_{2}\left(\mathrm{~mL} \cdot \mathrm{kg}^{-1} \cdot \mathrm{min}^{-1}\right)$ & 67.3 & 70.8 & 67.8 \\
$\mathrm{VO}_{2}(\mathrm{~L} / \mathrm{min})$ & 5.10 & 5.48 & 5.28 \\
Work rate $(\mathrm{W})$ & 325.1 & 324.7 & 323.7 \\
Rating of perceived exertion & 17.2 & 15.0 & 14.8 \\
Glucose $_{\text {Fast }}(\mathrm{mmol})$ & 4.28 & 4.79 & 4.85 \\
Glucose $_{\text {Postex }}(\mathrm{mmol})$ & 6.32 & 6.91 & 6.23 \\
Resting lactate $(\mathrm{mmol})_{\text {Postexercise lactate }(\mathrm{mmol})}$ & 0.86 & 1.10 & 1.27 \\
Insulin & 8.69 & 12.05 & 11.05 \\
C-reactive protein & 0.9 & 1.3 & 1.9 \\
\hline
\end{tabular}

ammediately before grain-based diet. 


\section{Daily Training and Subjective Daily Experiences}

The athlete reported fewer problems associated with his training on the GB diet. He reported cutting 2 workouts short while on the GB diet because of lethargy, fatigue, and muscle soreness. Training-log commentary on other subjective experiences of training and eating during the GB diet was similar to that for the ad libitum dietary period.

While training on the LC diet, the athlete experienced and reported the following atypical feelings and symptoms, which he described in his training log.

Frequent Experiences. After the third day of the LC diet, lethargy and fatigue were mentioned nearly every day in the training log. When monitored or measured by the athlete during training, HR and/or speed for a given RPE was lower than normal. Conversely, perceived exertion for a given speed or heart rate was higher than normal. The athlete reported frequent cravings for sweets, which he attempted to satisfy via artificially sweetened soft drinks and other artificially sweetened foods. He also reported frequent nighttime urination, which interrupted sleep on most nights, and persistent muscle soreness, even after days of reduced training volume and intensity. The athlete frequently reported worries about compromising his health, especially concerning lack of fiber and excess protein, saturated fat, and cholesterol consumption. Similarly, he noted the psychological difficulty of adhering to the LC diet when faced with frequently unsatisfactory workouts, feelings of physical depletion postworkout, cupboards and refrigerator full of his typical foods, and when grocery shopping or eating at restaurants.

Less Frequent Experiences. Poor mood and grumpiness were reported on 4 days. Constipation was reported on 3 days, and night sweats were reported 3 times. The athlete reported feelings of inhibited recovery and muscle weakness on 4 occasions. Finally, he recorded feeling a decreased ability to concentrate and what he reported as persistent "foggy thinking" on 2 days.

\section{Adherence to Training Plan}

Table 4 shows the training volumes and intensity of workouts during both diets and during the ad libitum period of training. The athlete recorded 6 instances of cutting his planned workout short during the LC diet, compared with 2 instances for the GB diet and 1 for the ad libitum diet. He recorded 5 instances of purposefully reducing the training intensity from a planned high-intensity workout during the LC period of training, compared with zero instances of intensity reduction on the GB diet and 1 in the ad libitum condition.

\section{Discussion}

Because this research is a case study of observations from a clinical study, there were no statistical analyses performed. All quantitative data herein are offered solely as demonstrative observations of how LC and GB diets affected this endurance athlete compared with his usual ad libitum high-carbohydrate diet. The observations of this case study indicate that it was possible, although not without difficulty, for this elite endurance athlete to adhere to a LC diet and to lose weight while following a 
Table 4 Daily Training Mode, Duration, and Intensity for Each Dietary Condition ${ }^{a}$

\begin{tabular}{|c|c|c|c|}
\hline \multirow[b]{2}{*}{ Day } & \multicolumn{3}{|c|}{ Diet } \\
\hline & Low carbohydrate & Grain based & Ad libitum \\
\hline 1 & $\begin{array}{l}\text { Bike, } 60 \mathrm{~min} \text {, high } \\
\text { Run, } 14 \mathrm{~min} \text {, low }\end{array}$ & $\begin{array}{l}\text { Bike, } 150 \text { min, high } \\
\text { Run, } 22 \text { min, low }\end{array}$ & $\begin{array}{l}\text { Bike, } 30 \mathrm{~min} \text {, low } \\
\text { Other, } 25 \mathrm{~min} \text {, low } \\
\text { Run, } 25 \mathrm{~min} \text {, low }\end{array}$ \\
\hline 2 & $\begin{array}{l}\text { Run, } 74 \mathrm{~min} \text {, low } \\
\text { Swim, } 16 \mathrm{~min} \text {, low }\end{array}$ & $\begin{array}{l}\text { Run, } 48 \mathrm{~min} \text {, high } \\
\text { Bike, } 120 \mathrm{~min} \text {, low }\end{array}$ & $\begin{array}{l}\text { Bike, } 45 \mathrm{~min} \text {, low } \\
\text { Swim, } 55 \mathrm{~min} \text {, high }\end{array}$ \\
\hline 3 & $\begin{array}{l}\text { Bike, } 30 \mathrm{~min} \text {, low } \\
\text { Swim, } 60 \mathrm{~min} \text {, low }\end{array}$ & $\begin{array}{l}\text { Run, } 87 \mathrm{~min} \text {, low } \\
\text { Swim, } 15 \mathrm{~min} \text {, low }\end{array}$ & $\begin{array}{l}\text { Bike, } 30 \mathrm{~min} \text {, low } \\
\text { Run, } 60 \mathrm{~min} \text {, high }\end{array}$ \\
\hline 4 & $\begin{array}{l}\text { Bike, } 30 \mathrm{~min} \text {, low } \\
\text { Swim, } 60 \mathrm{~min}, \text { low }^{\mathrm{b}}\end{array}$ & $\begin{array}{l}\text { Swim, } 60 \mathrm{~min} \text {, low } \\
\text { Bike, } 30 \mathrm{~min} \text {, low } \\
\text { Other, } 20 \mathrm{~min} \text {, low }\end{array}$ & $\begin{array}{l}\text { Bike, } 30 \mathrm{~min} \text {, low } \\
\text { Swim, } 60 \mathrm{~min} \text {, low }\end{array}$ \\
\hline 5 & $\begin{array}{l}\text { Run, } 45 \text { min, low }{ }^{b} \\
\text { Bike, } 0 \text { min }^{\mathrm{c}} \\
(30 \mathrm{~min})\end{array}$ & $\begin{array}{l}\text { Swim, } 56 \text { min, high } \\
\text { Run, } 21 \mathrm{~min} \text {, low }\end{array}$ & $\begin{array}{l}\text { Swim, } 50 \mathrm{~min} \text {, low } \\
\text { Bike, } 150 \mathrm{~min} \text {, high }\end{array}$ \\
\hline 6 & $\begin{array}{l}\text { Bike, } 30 \mathrm{~min} \text {, low } \\
\text { Swim, } 16 \mathrm{~min}, \text { low }^{\mathrm{c}} \\
(40 \mathrm{~min})\end{array}$ & Run, $67 \mathrm{~min}$, high & $\begin{array}{l}\text { Bike, } 60 \mathrm{~min} \text {, low } \\
\text { Other, } 20 \mathrm{~min} \text {, low }\end{array}$ \\
\hline 7 & $\begin{array}{l}\text { Bike, } 30 \mathrm{~min} \text {, low } \\
\text { Other, } 30 \mathrm{~min} \text {, high }\end{array}$ & $\begin{array}{l}\text { Bike, } 30 \mathrm{~min} \text {, low } \\
\text { Swim, } 48 \mathrm{~min} \text {, low } \\
\text { Other, } 20 \mathrm{~min} \text {, high }\end{array}$ & $\begin{array}{l}\text { Run, } 90 \mathrm{~min} \text {, low } \\
\text { Swim, } 0 \min ^{\mathrm{c}}(15 \mathrm{~min})\end{array}$ \\
\hline 8 & $\begin{array}{l}\text { Bike, } 90 \mathrm{~min}, l^{\mathrm{b}} \\
\text { Run, } 14 \mathrm{~min}, \mathrm{low}^{\mathrm{c}} \\
(14 \mathrm{~min})\end{array}$ & $\begin{array}{l}\text { Bike, } 180 \mathrm{~min} \text {, high } \\
\text { Run, } 27 \mathrm{~min} \text {, low }\end{array}$ & $\begin{array}{l}\text { Run, } 29 \mathrm{~min} \text {, low } \\
\text { Bike, } 30 \mathrm{~min} \text {, low }\end{array}$ \\
\hline 9 & $\begin{array}{l}\mathrm{R}, 75 \mathrm{~min}, \text { low } \\
\text { Swim, } 0 \mathrm{~min}^{\mathrm{c}} \\
(16 \mathrm{~min})\end{array}$ & Run, 14 min, low & $\begin{array}{l}\text { Bike, } 30 \mathrm{~min} \text {, low } \\
\text { Swim, } 60 \mathrm{~min} \text {, high } \\
\text { Other, } 30 \mathrm{~min} \text {, high }\end{array}$ \\
\hline
\end{tabular}

(continued)

typical training program designed to optimize performance. It appears, however, that high-intensity training and performance were negatively affected during the 2 wk of LC diet. On the LC diet, the athlete experienced psychosomatic symptoms, feelings of lethargy, and untoward physiological outcomes during the standardized $5-\mathrm{km}$ cycling performance. This performance ride was designed to represent both higher intensity training and a typical intensity experienced during competition. Furthermore, the athlete's daily training program during the LC diet was negatively affected compared with the GB and ad libitum diets-workouts were cut short more frequently or were reduced in intensity from what was originally planned. These observations are akin to research on runners with varying levels of carbohydrate in 
Table 4 (continued)

\begin{tabular}{|c|c|c|c|}
\hline \multirow[b]{2}{*}{ Day } & \multicolumn{3}{|c|}{ Diet } \\
\hline & Low carbohydrate & Grain based & Ad libitum \\
\hline 10 & $\begin{array}{l}\text { Bike, } 30 \mathrm{~min} \text {, low } \\
\text { Run, } 30 \mathrm{~min} \text {, low } \\
\text { Swim, } 55 \mathrm{~min} \text {, low }\end{array}$ & $\begin{array}{l}\text { Rụ, } \\
\text { min }) \\
\text { Swim, } 06 \min ^{\mathrm{c}}(55 \mathrm{~min})\end{array}$ & $\begin{array}{l}\text { Run, } 60 \mathrm{~min}, \text { low }^{\mathrm{b}} \\
\text { Bike, } 30 \mathrm{~min} \text {, low }\end{array}$ \\
\hline 11 & $\begin{array}{l}\text { Bike, } 45 \mathrm{~min} \text {, low } \\
\text { Swim, } 50 \mathrm{~min}, \text { low }^{\mathrm{b}}\end{array}$ & $\begin{array}{l}\text { Run, } 42 \mathrm{~min} \text {, low } \\
\text { Bike, } 115 \mathrm{~min} \text {, low } \\
\text { Other, } 25 \mathrm{~min} \text {, high }\end{array}$ & $\begin{array}{l}\text { Bike, } 30 \mathrm{~min} \text {, low } \\
\text { Swim, } 64 \mathrm{~min} \text {, low }\end{array}$ \\
\hline 12 & $\begin{array}{l}\text { Swim, } 15 \mathrm{~min}, \text { low }^{\mathrm{c}} \\
(35 \mathrm{~min}) \\
\text { Bike, } 30 \mathrm{~min} \text {, low } \\
\text { Other, } 20 \mathrm{~min} \text {, low }\end{array}$ & Off & $\begin{array}{l}\text { Swim, } 50 \mathrm{~min} \text {, low } \\
\text { Bike, } 170 \mathrm{~min} \text {, high } \\
\text { Run, } 13 \mathrm{~min} \text {, low }\end{array}$ \\
\hline 13 & $\begin{array}{l}\text { Bike, } 40 \mathrm{~min} \text {, low } \\
\text { Run, } 51 \mathrm{~min} \text {, high } \\
\text { Other, } 30 \mathrm{~min} \text {, low }\end{array}$ & $\begin{array}{l}\text { Bike, } 30 \mathrm{~min} \text {, low } \\
\text { Swim, } 57 \mathrm{~min} \text {, low }\end{array}$ & $\begin{array}{l}\text { Run, } 15 \text { min, low } \\
\text { Bike, } 40 \mathrm{~min} \text {, low } \\
\text { Run, } 54 \text { min, high }\end{array}$ \\
\hline 14 & $\begin{array}{l}\text { Bike, } 130 \mathrm{~min}, \mathrm{low}^{\mathrm{d}} \\
(20 \mathrm{~min}) \\
\text { Other, } 15 \mathrm{~min} \text {, low }\end{array}$ & $\begin{array}{l}\text { Bike, } 30 \mathrm{~min} \text {, low } \\
\text { Swim, } 45 \mathrm{~min} \text {, high }\end{array}$ & $\begin{array}{l}\text { Bike, } 36 \mathrm{~min} \text {, low } \\
\text { Run, } 60 \mathrm{~min} \text {, low } \\
\text { Swim, } 20 \mathrm{~min} \text {, low }\end{array}$ \\
\hline Total & $\begin{array}{l}1215 \min =20: 15 \text { out } \\
\text { of planned } \sim 23: 20, \\
\text { 3/8 high-intensity } \\
\text { workouts. }\end{array}$ & $\begin{array}{l}1425 \text { min }=23: 45 \\
\text { out of planned } \sim 25 \\
\text { h, } 8 / 8 \text { high-intensity } \\
\text { workouts. }\end{array}$ & $\begin{array}{l}1551 \text { min }=25: 51 \\
\text { out of planned } \sim 25 \\
\text { h, } 7 / 8 \text { high-intensity } \\
\text { workouts. }\end{array}$ \\
\hline
\end{tabular}

${ }^{a}$ Other indicates resistance training or other cross-training; swimming low intensity $=1: 18-1: 30$ per 100 -yd average pace of workout; swimming high intensity $<1: 18$ per 100 -yd average pace of workout; bicycling low intensity = heart rate below 160 for entire ride (approximately $22 \mathrm{miles} / \mathrm{h}$ ); bicycling high intensity = heart rate above 160 for at least 5 min of ride; running low intensity = heart rate below 160 for entire run (approximately 6:30/mile); running high intensity = heart rate above 160 for at least 5 min of run.

'Intensity lowered from planned high-intensity workout.

${ }^{c}$ Workout cut short (by time in minutes).

dintensity lowered and workout cut short (by time in minutes).

their diet during intense training (1). Because none of the dietary conditions came with restrictions on total energy intake, the LC diet could theoretically meet the carbohydrate requirements needed to support heavy training, provided the athlete ate enough food.

One issue illustrated by this case study is how much influence alterations in the daily exercise regimen could have had on the subsequent postintervention performance test. This study might serve as a preliminary call for future dietary interventions examining exercise-performance outcomes to track daily training. Such tracking might ensure that similar work is being performed from trial to trial. If study volunteers are basing training intensity and work rate on RPE or HR, they 
might not be completing similar amounts of work, which ultimately might elicit diet-independent myocellular adaptations. Over time, this could detrimentally affect postintervention assessments and confound study results.

In accordance with previous work by Jarvis et al. (15), our athlete decreased body mass and showed decreased athletic performance after an LC diet. The results of the present study extend the work of Jarvis et al. (15) - the observations of this athlete were compared with another dietary condition, whereas the Jarvis et al. study compared performance after an energy-deficit diet only with an ad libitum diet. Lambert et al. (19) indicated that it should not be surprising to observe a decrement in exercise performance with short-term exposure to an LC, high-fat diet. Erlenbusch et al. (9) suggested that LC dietary changes less than a week in length might demonstrate decreased glycogen status but no evident metabolic effects. Previous studies have demonstrated positive metabolic adaptations to high-fat diets in 2 wk or less $(17,19)$. Given the equivocal outcomes observed in the literature and further supported in this case study, carbohydrate restriction $(<25 \%)$ by athletes attempting to lose weight or increase endurance performance should be undertaken with caution, if at all.

Regarding body-composition changes, the subject of this study unintentionally lost body fat, weight, and some fat-free mass during the LC condition as his percentage body fat decreased from $8 \%$ to $6.4 \%$. It is noteworthy that these data indicate that the athlete lost $1 \mathrm{~kg}$ of fat-free mass during the LC diet, despite higher protein intake. This loss might have been from reduced cell size as a result of glycogen depletion, lower levels of body water (hydration status was not monitored in this study), actual muscle-tissue loss, or artifact in the dual-X-ray-absorptiometry analysis. Despite no volitional restrictions on protein, fat, or total volume of food in the LC diet, the athlete consumed far fewer calories than during a period of ad libitum eating. The discrepancy in energy intake ( $900 \mathrm{kcal} / \mathrm{d})$, however, probably does not fully account for the amount of weight lost. It is likely that a good portion of the weight lost on the LC diet was from loss of body water, especially that bound to muscle glycogen (2).

The HR (averaged over $20 \mathrm{~min}$ ) and RPE values seem to indicate that the GB diet and ad libitum diet were superior to the LC diet with regard to cycling performance at a higher intensity. For this athlete, a 5-km ride at an HR around 180 beats/min is less taxing than his actual competitive event, and methodologies employing a longer high-intensity cycling test in this study might have revealed a greater dietary effect on the physiological parameters. Training-log information also supports these testing data, in that training speeds were generally slower at any given HR or RPE on the LC diet. What is not known from the present data is whether such an observed difference is from the dietary intake per se or whether training might serve as a mediator in such a relationship between diet and postintervention performance. Furthermore, it is unknown whether a short-term decrement in performance might be replaced with a "rebound" ergogenic effect, should the athlete return to a carbohydrate-replete diet. Although some evidence (18) suggests this possibility, this athlete reported experiencing more of a gradual return to normalcy than an ergogenic rebound (data not shown). Recent literature $(7,11)$ seems to suggest no endurance-performance benefit from low-carbohydrate, highfat diets, despite an increase in fat utilization. 
In terms of health, the American Heart Association and American Dietetic Association have called for caution regarding LC diets, because of potential risks such as bone-mineral loss, hyperlipidemia, and fatigue (23). Although the values for this athlete were still in the "normal" range, total cholesterol and LDL-C both increased during the LC diet. These findings are in opposition to some promoters of low-carbohydrate lifestyles, in that LC diets are purported not only to reduce weight but also to improve health-including blood lipid profiles. It may be that overweight or obese individuals (those most likely to adopt a low-carbohydrate lifestyle) experience improvements in lipoproteins because they tend to have high lipoprotein levels when beginning a lifestyle modification. Certain health-related aspects did improve in our athlete on the LC diet, including decreased triglyceride and insulin and increased HDL-C levels. The last of these likely increased to transport and offset rising LDL. The outcomes observed here were in line with the review by Onega (23). Finally, although it was not directly measured in the present study, insulin sensitivity most likely did improve on the LC diet, as evidenced by the lower insulin, blood glucose, and triglyceride levels.

The present case study has a number of limitations. First, because it is a case study of a single elite endurance athlete, external validity is minimal. Second, it is not known whether the dietary manipulation itself or the specific characteristics of each diet actually caused apparent differences observed at the end of each diet. Radical departures from the typical diet might result in effects such as those observed in the present study, regardless of macronutrient content. Third, there might be an order effect at work, because the LC diet preceded the GB diet and because the cardiorespiratory fitness of the athlete improved over the 7-wk intervention period. It is conceivable that training on the LC diet stimulated changes in substrate metabolism for this athlete, because others have reported enhanced fat oxidation after higher fat diets (19). Fourth, the dietary data were self-reported, so errors, omissions, or other forms of bias must be considered. Finally, neither the researchers nor the subject was blind to the condition, which could influence such variables as perceived exertion, subjective daily experiences, and training volumes and intensity.

Future research should assess health and fitness outcomes along with the ability of the "fitness exerciser" to adhere to an exercise routine under varying dietary conditions. Many questions remain unanswered regarding the effects of weight-loss diets on athletic performance and health in both the short term and the long term. As illustrated by the triathlete in the present study, there was an incompatibility between LC eating and high-intensity training. Therefore, a practical question for athletes and fitness exercisers might be whether dietary restriction is necessary in efforts to improve fitness, health, or body composition.

With relevant literature and this study's observations and limitations in mind, and given the high number of fitness exercisers currently attempting to lose weight, what should be recommended with regard to a diet supportive of health and an exercise routine? On one hand, an LC diet has hereby been shown to allow weight loss even for a lean athlete consuming $3700 \mathrm{kcal} / \mathrm{d}$ in training. On the other hand, mood, daily athletic training, and HR and RPE during higher intensity exercise seem to be negatively affected while on such a diet. Blood lipids may or may not be a concern, depending on the individual's current health status or lipoprotein-lipid 
profile. Insulin sensitivity improved on the LC diet, which has been reported by others (3), but insulin sensitivity also improves via exercise alone (14). Thus, we might be left with the fence-sitting position typified by Bravata et al. (5) that there is insufficient evidence at this time to make definitive recommendations for or against LC diets. Alternatively, we could argue along the lines of Onega (23) that LC diets are associated with potential health risks and poor athletic performance. Because there is currently little evidence to support the use of LC or high-fat diets by athletes, and the long-term health effects of such diets are unknown $(9,16)$, there appears to be no compelling argument for athletes or perhaps even serious exercisers to employ such diets.

\section{Acknowledgments}

This project was supported by a research assistantship through the Community Health Institute at KSU and by a research grant from the Kansas Wheat Commission.

\section{References}

1. Achten, J., S.L. Halson, L. Moseley, M.P. Rayson, A. Casey, and A.E. Jeukendrup. Higher dietary carbohydrate content during intensified running training results in better maintenance of performance and mood state. J. Appl. Physiol. 96(4):1331-1340, 2004.

2. Astrup, A., T. Meinert Larsen, and A. Harper. Atkins and other low-carbohydrate diets: hoax or an effective tool for weight loss? Lancet. 364(9437):897-899, 2004.

3. Boden, G., K. Sargrad, C. Homko, M. Mozzoli, and T.P. Stein. Effect of a low-carbohydrate diet on appetite, blood glucose levels, and insulin resistance in obese patients with type 2 diabetes. Ann. Intern. Med. 142(6):403-411, 2005.

4. Borg, G.A. Perceived exertion. Exerc. Sport Sci. Rev. 2:131-153, 1974.

5. Bravata, D.M., L. Sanders, J. Huang, et al. Efficacy and safety of low-carbohydrate diets: a systematic review. JAMA. 289(14):1837-1850, 2003.

6. Brownell, K.D., S.N. Steen, and J.H. Wilmore. Weight regulation practices in athletes: analysis of metabolic and health effects. Med. Sci. Sports Exerc. 19(6):546-556, 1987.

7. Burke, L.M., and B. Kiens. "Fat adaptation" for athletic performance: the nail in the coffin? J. Appl. Physiol. 100(1):7-8, 2006.

8. Cheuvront, S.N. The Zone Diet phenomenon: a closer look at the science behind the claims. J. Am. Coll. Nutr. 22(1):9-17, 2003.

9. Erlenbusch, M., M. Haub, K. Munoz, S. MacConnie, and B. Stillwell. Effect of high-fat or high-carbohydrate diets on endurance exercise: a meta-analysis. Int. J. Sport Nutr. Exerc. Metab. 15(1):1-14, 2005.

10. Friedewald, W.T., R.I. Levy, and D.S. Fredrickson. Estimation of the concentration of low-density lipoprotein cholesterol in plasma, without use of the preparative ultracentrifuge. Clin. Chem. 18(6):499-502, 1972.

11. Havemann, L., S.J. West, J.H. Goedecke, et al. Fat adaptation followed by carbohydrate loading compromises high-intensity sprint performance. J. Appl. Physiol. 100(1):194202, 2006.

12. Helge, J.W., P.W. Watt, E.A. Richter, M.J. Rennie, and B. Kiens. Fat utilization during exercise: adaptation to a fat-rich diet increases utilization of plasma fatty acids and very low density lipoprotein-triacylglycerol in humans. J. Physiol. 537(Pt 3):1009-1020, 2001 . 
13. Horvath, P.J., C.K. Eagen, N.M. Fisher, J.J. Leddy, and D.R. Pendergast. The effects of varying dietary fat on performance and metabolism in trained male and female runners. J. Am. Coll. Nutr. 19(1):52-60, 2000.

14. Houmard, J.A., C.D. Shaw, M.S. Hickey, and C.J. Tanner. Effect of short-term exercise training on insulin-stimulated PI 3-kinase activity in human skeletal muscle. Am. J. Physiol. 277(6 Pt 1):E1055-E1060, 1999.

15. Jarvis, M., L. McNaughton, A. Seddon, and D. Thompson. The acute 1-week effects of the Zone diet on body composition, blood lipid levels, and performance in recreational endurance athletes. J. Strength Cond. Res. 16(1):50-57, 2002.

16. Jeukendrup, A. High-carbohydrate versus high-fat diets in endurance sports. Sportmed. Sporttraumatol. 51(1):17-23, 2003.

17. Koutsari, C., and L.S. Sidossis. Effect of isoenergetic low- and high-carbohydrate diets on substrate kinetics and oxidation in healthy men. Br. J. Nutr. 90(2):413-418, 2003.

18. Lambert, E.V., J.H. Goedecke, C. Zyle, et al. High-fat diet versus habitual diet prior to carbohydrate loading: effects of exercise metabolism and cycling performance. Int. J. Sport Nutr. Exerc. Metab. 11(2):209-225, 2001.

19. Lambert, E.V., J.A. Hawley, J. Goedecke, T.D. Noakes, and S.C. Dennis. Nutritional strategies for promoting fat utilization and delaying the onset of fatigue during prolonged exercise. J. Sports Sci. 15(3):315-324, 1997.

20. Lambert, E.V., D.P. Speechly, S.C. Dennis, and T.D. Noakes. Enhanced endurance in trained cyclists during moderate intensity exercise following 2 weeks adaptation to a high fat diet. Eur. J. Appl. Physiol. Occup. Physiol. 69(4):287-293, 1994.

21. Muoio, D.M., J.J. Leddy, P.J. Horvath, A.B. Awad, and D.R. Pendergast. Effect of dietary fat on metabolic adjustments to maximal $\mathrm{VO}_{2}$ and endurance in runners. Med. Sci. Sports Exerc. 26(1):81-88, 1994.

22. Odland, L.M., G.J. Heigenhauser, D. Wong, M.G. Hollidge-Horvat, and L.L. Spriet. Effects of increased fat availability on fat-carbohydrate interaction during prolonged exercise in men. Am. J. Physiol. 274(4 Pt 2):R894-R902, 1998.

23. Onega, T. Does a low-carbohydrate diet affect biomarkers for CVD? JAAPA. 17(4):4446, 2004.

24. Pernow, B., and B. Saltin. Availability of substrates and capacity for prolonged heavy exercise in man. J. Appl. Physiol. 31(3):416-422, 1971.

25. Pitsiladis, Y.P., C. Duignan, and R.J. Maughan. Effects of alterations in dietary carbohydrate intake on running performance during a $10 \mathrm{~km}$ treadmill time trial. $B r . J$. Sports Med. 30(3):226-231, 1996.

26. Pitsiladis, Y.P., and R.J. Maughan. The effects of alterations in dietary carbohydrate intake on the performance of high-intensity exercise in trained individuals. Eur. J. Appl. Physiol. Occup. Physiol. 79(5):433-442, 1999.

27. Position of the American Dietetic Association, Dietitians of Canada, and the American College of Sports Medicine: Nutrition and athletic performance. J. Am. Diet. Assoc. 100(12):1543-1556, 2000.

28. van Loon, L.J., and B.H. Goodpaster. Increased intramuscular lipid storage in the insulin-resistant and endurance-trained state. Pflugers Arch. 451(5):606-616, 2006.

29. Webber, J. Energy balance in obesity. Proc. Nutr. Soc. 62(2):539-543, 2003.

30. Westman, E.C., W.S. Yancy, Jr, M.D. Haub, and J.S. Volek. Insulin Resistance from a low carbohydrate, high fat diet perspective. Metab. Syndr. Rel. Disord. 3:14-18, 2005.

31. Williams, C., J. Brewer, and M. Walker. The effect of a high carbohydrate diet on running performance during a 30-km treadmill time trial. Eur. J. Appl. Physiol. Occup. Physiol. 65(1):18-24, 1992.

32. Yancy, W.S., Jr, M.K. Olsen, J.R. Guyton, R.P. Bakst, and E.C. Westman. A low-carbohydrate, ketogenic diet versus a low-fat diet to treat obesity and hyperlipidemia: a randomized, controlled trial. Ann. Intern. Med. 140(10):769-777, 2004. 